For numbered affiliations see end of article.

Correspondence to: R Siemieniuk reed.siemieniuk@medportal.ca https://orcid.org/0000-0002-3725-3031 Additional material is published online only. To view please visit the journal online

Cite this as: BMJ 2021;374:n2231 http://dx.doi.org/10.1136/bmj.n2231 Accepted: 10 September 2021

\title{
Antibody and cellular therapies for treatment of covid-19: a living systematic review and network meta-analysis
}

Reed AC Siemieniuk, 1, 2, * Jessica J Bartoszko, 1, " Juan Pablo Díaz Martinez, 1, " Elena Kum, 1, * Anila Qasim, 1 , * Dena Zeraatkar, 1, * Ariel Izcovich, ${ }^{3}$ Sophia Mangala, ${ }^{1}$ Long Ge, ${ }^{4}$ Mi Ah Han, ${ }^{5}$ Thomas Agoritsas, 1,6 Donald Arnold, ${ }^{2}$ Camila Ávila, ${ }^{7}$ Derek K Chu, ${ }^{1,2}$ Rachel Couban, ${ }^{8}$ Ellen Cusano, ${ }^{9}$ Andrea J Darzi, ${ }^{1}$ Tahira Devji, ${ }^{10}$ Farid Foroutan, ${ }^{11}$ Maryam Ghadimi, ${ }^{1}$ Assem Khamis, ${ }^{12}$ Francois Lamontagne, ${ }^{13}$ Mark Loeb, ${ }^{1}$ ${ }^{2}$ Anna Miroshnychenko, ${ }^{1}$ Sharhzad Motaghi, ${ }^{1}$ Srinivas Murthy, ${ }^{14}$ Reem A Mustafa, 1,15 Gabriel Rada, ${ }^{7}$ Bram Rochwerg, ${ }^{1,2}$ Charlotte Switzer, ${ }^{1}$ Per O Vandvik, ${ }^{16}$ Robin WM Vernooij, ${ }^{17,18}$ Ying Wang, ${ }^{1}$ Liang Yao, Gordon H Guyatt, 1,2 Romina Brignardello-Petersen

\section{ABSTRACT}

\section{OBJECTIVE}

To evaluate the efficacy and safety of antiviral antibody therapies and blood products for the treatment of novel coronavirus disease 2019 (covid-19).

DESIGN

Living systematic review and network meta-analysis, with pairwise meta-analysis for outcomes with insufficient data.

\section{DATA SOURCES}

WHO covid-19 database, a comprehensive multilingual source of global covid-19 literature, and six Chinese databases (up to 21 July 2021).

\section{STUDY SELECTION}

Trials randomising people with suspected, probable, or confirmed covid-19 to antiviral antibody therapies, blood products, or standard care or placebo. Paired reviewers determined eligibility of trials independently and in duplicate.

\section{METHODS}

After duplicate data abstraction, we performed random effects bayesian meta-analysis, including network meta-analysis for outcomes with sufficient data. We assessed risk of bias using a modification of the Cochrane risk of bias 2.0 tool. The certainty of the evidence was assessed using the grading of recommendations assessment, development, and evaluation (GRADE) approach. We meta-analysed interventions with $\geq 100$ patients randomised or $\geq 20$ events per treatment arm.

\section{RESULTS}

As of 21 July 2021, we identified 47 trials evaluating convalescent plasma ( 21 trials), intravenous immunoglobulin (IVIg) (5 trials), umbilical cord mesenchymal stem cells ( 5 trials), bamlanivimab (4 trials), casirivimab-imdevimab (4 trials),

bamlanivimab-etesevimab (2 trials), control plasma (2 trials), peripheral blood non-haematopoietic enriched stem cells ( 2 trials), sotrovimab (1 trial), anti-SARS-CoV-2 IVIg (1 trial), therapeutic plasma exchange (1 trial), XAV-19 polyclonal antibody (1 trial), CT-P59 monoclonal antibody (1 trial) and INMoo5 polyclonal antibody (1 trial) for the treatment of covid-19. Patients with non-severe disease randomised to antiviral monoclonal antibodies had lower risk of hospitalisation than those who received placebo: casirivimab-imdevimab (odds ratio (OR) 0.29 (95\% Cl 0.17 to 0.47); risk difference (RD) $-4.2 \%$; moderate certainty), bamlanivimab (OR 0.24 (0.06 to 0.86 ); RD $-4.1 \%$; low certainty), bamlanivimab-etesevimab (OR 0.31 (0.11 to o.81); RD -3.8\%; low certainty), and sotrovimab (OR 0.17 (0.04 to 0.57); RD -4.8\%; low certainty). They did not have an important impact on any other outcome. There was no notable difference between monoclonal antibodies. No other intervention had any meaningful effect on any outcome in patients with non-severe covid-19. No intervention, including antiviral antibodies, had an important impact on any outcome in patients with severe or critical covid-19, except casirivimab-imdevimab, which may reduce mortality in patients who are seronegative.

\section{CONCLUSION}

In patients with non-severe covid-19, casirivimab-imdevimab probably reduces hospitalisation; bamlanivimab-etesevimab, bamlanivimab, and sotrovimab may reduce hospitalisation. Convalescent plasma, IVIg, and other antibody and cellular interventions may not confer any meaningful benefit.

\section{SYSTEMATIC REVIEW REGISTRATION}

This review was not registered. The protocol established a priori is included as a data supplement. FUNDING

This study was supported by the Canadian Institutes of Health Research (grant CIHR- IRSC:0579001321). READERS' NOTE

This article is a living systematic review that will be updated to reflect emerging evidence. Interim updates and additional study data will be posted on our website (www.covid19lnma.com).

\section{Introduction}

Global cases of coronavirus disease 2019 (covid-19) continue to rise. As of 14 September 2021, more than 225 million people have been infected with severe acute respiratory syndrome coronavirus virus 2 (SARS-CoV-2), and total deaths have surpassed 4.6 million. ${ }^{1}$ Because covid-19 represents a significant threat to global health, coordinated international efforts to identify evidence based therapies have resulted in over 2900 registered clinical trials. Approximately $12 \%$ of these trials are investigating cellular or antibody-based therapies such as convalescent plasma, intravenous immunoglobulins (IVIg), or antiviral antibodies. ${ }^{2}$ 
Given their favourable toxicity profile and historical (though variable) mortality benefit when used in patients with SARS-CoV-1, 1918 pandemic Spanish influenza A, influenza H1N1, influenza $\mathrm{H}_{5} \mathrm{~N} 1$, respiratory syncytial virus, and Ebola virus disease, these harvested and manufactured antiviral antibodies represent attractive therapeutic options for covid-19. ${ }^{3-6}$ Indeed, based on this historical evidence combined with early clinical trial data, several countries have issued authorisation for emergency use of convalescent plasma for the treatment of hospitalised patients with covid-19. Several countries have also authorised the use of antiviral monoclonal antibodies of covid-19. ${ }^{7}$

Unlike drugs, stem cells, convalescent plasma, and IVIg cannot be manufactured; thus, production is limited by the number of donors. Since these products have established therapeutic applications in the treatment of congenital and acquired diseases, ${ }^{8}$ one can, in the absence of clear evidence for use in covid-19, anticipate challenges related to resource allocation. In contrast, monoclonal antibodies are very easily scalable once they are identified, but production can be time consuming. ${ }^{9}$ Therefore, in the midst of a global pandemic in which resource management is fundamental, timely summaries of available evidence and associated guidelines are crucial. ${ }^{10}$

This living systematic review complements the published living systematic review and network meta-analysis comparing the effects of drug treatments ${ }^{11}$ and prophylaxis ${ }^{12}$ for covid-19. A living systematic review is dynamic and captures all relevant data published over time. ${ }^{13}$ Network meta-analysis, which combines direct and indirect evidence to compare interventions, can provide robust information regarding the relative efficacy of interventions that may not have been compared head-to-head due to feasibility or other constraints. ${ }^{14}$

The present living systematic review and network meta-analysis is part of the BMJ Rapid Recommendations project, a collaboration between the MAGIC Evidence Ecosystem Foundation (www.magicproject.org) and The BMJ. This living network meta-analysis will inform a collaborative living guideline from the World Health Organization, BMJ, and MAGIC Evidence Ecosystem Foundation. ${ }^{15}$ Data will inform WHO and BMJ Rapid Recommendations ${ }^{15-17}$ to deliver trustworthy and potentially practice-changing evidence to both clinicians and patients.

\section{Methods}

A protocol provides the detailed methods of this systematic review, including all updates (see supplementary data on bmj.com). We report this living systematic review following the guidelines of the preferred reporting items for systematic reviews and meta-analyses (PRISMA) checklist for pairwise ${ }^{18} 19$ and network meta-analyses. ${ }^{20}$ A living systematic review is a cumulative synthesis that is updated regularly as new evidence becomes available. ${ }^{21}$ The WHO living guideline panel provided guidance on decisions relevant to data synthesis.

\section{Eligibility criteria}

We included randomised trials in people with suspected, probable, or confirmed covid-19 that compared blood products and covid-19-specific antiviral antibodies against one another or against no intervention, placebo, or standard care. We included trials regardless of publication status (peer reviewed, in press, or preprint) or language. No restrictions were applied based on severity of illness or setting.

We excluded randomised trials evaluating vaccines, pharmacologic drugs, nutrition, traditional Chinese herbal medicines, and non-drug supportive care interventions. We identified and separately categorised trials including patients with covid-19 that evaluated these interventions. Randomised trials evaluating drug treatments ${ }^{11}$ and prophylaxis ${ }^{12}$ for covid-19 were synthesised in separate living network meta-analyses. We excluded non-randomised trials.

\section{Information sources}

We perform daily searches from Monday to Friday in the WHO global literature on covid-19 database. Before its merging with the WHO global literature on covid-19 database on 9 October 2020, we performed daily searches from Monday to Friday in the US Centers for Disease Control and Prevention (CDC) covid-19 Research Articles Downloadable Database for eligible studies. ${ }^{22}$ The database includes 25 bibliographic and grey literature sources: Medline (Ovid and PubMed), PubMed Central, Embase, CAB Abstracts, Global Health, PsycInfo, Cochrane Library, Scopus, Academic Search Complete, Africa Wide Information, CINAHL, ProQuest Central, SciFinder, the Virtual Health Library, LitCovid, WHO covid-19 website, CDC covid-19 website, Eurosurveillance, China CDC Weekly, Homeland Security Digital Library, ClinicalTrials.gov, bioRxiv (preprints), medRxiv (preprints), chemRxiv (preprints), and SSRN (preprints).

The daily searches are designed to match the update schedule of the database and to capture eligible studies the day of or the day after publication. To identify randomised controlled trials, we filter the results from the WHO database through a validated and highly sensitive machine learning model. ${ }^{23}$ We track preprints of randomised controlled trials until publication and update data to match that in the peer reviewed publication when discrepant, and reconcile corrections and retractions if they exist.

In addition, we searched six Chinese databases: Wanfang, Chinese Biomedical Literature, China National Knowledge Infrastructure, VIP, Chinese Medical Journal Net (preprints), and ChinaXiv (preprints). We adapted the search terms for covid-19 developed by the CDC to the Chinese language. For the Chinese literature search, we also included search terms for randomised trials. The supplementary data include the Chinese literature search strategy.

We monitor living evidence retrieval services on an ongoing basis. These included the Living Overview of the Evidence (L-OVE) covid-19 Repository by the Epistemonikos Foundation ${ }^{24}$ and the Systematic and Living Map on covid-19 Evidence by the Norwegian Institute of Public Health, in collaboration with the Cochrane Canada Centre at McMaster University. ${ }^{25}$

We searched WHO information sources from 1 December 2019 to 21 July 2021, and the Chinese literature from inception to 20 February 2021.

\section{Study selection}

Using a systematic review software, Covidence, ${ }^{26}$ pairs of reviewers, following training and calibration exercises, independently screen all titles and abstracts, followed by full texts of trials that were identified as potentially eligible. A third reviewer adjudicates conflicts.

\section{Data collection}

For each eligible trial, pairs of reviewers, following training and calibration exercises, extract data independently using a standardised, pilot tested data extraction form. Reviewers collect information on trial characteristics (trial registration, publication status, study status, design), patient characteristics (country, age, sex, smoking habits, comorbidities, setting and type of care, severity of covid-19 symptoms, timing of therapy relative to symptom onset), donor characteristics (selection criteria, sex, severity of disease), and outcomes of interest (means or medians and measures of 
variability for continuous outcomes and the number of participants analysed and the number of participants who experienced an event for dichotomous outcomes). Reviewers resolve discrepancies by discussion and, when necessary, with adjudication by a third party.

Outcomes of interest were selected based on the clinical expertise of our systematic review team and by a guideline panel developing WHO and BMJ Rapid Recommendations. Selected outcomes include mortality (closest to 90 days), mechanical ventilation (total number of patients, over 90 days), adverse events leading to discontinuation (within 28 days), viral clearance (closest to 7 days \pm 3 days), transfusion-related acute lung injury (TRALI; total number of patients, within 28 days), transfusion-associated circulatory overload (TACO; total number of patients, within 28 days), infusion reactions (total number of patients, within 28 days), duration of hospitalisation, intensive care unit (ICU) length of stay, time to symptom resolution or clinical improvement, and time to viral clearance. Viral clearance at seven days and time to viral clearance were included because both may be surrogates for transmissibility. ${ }^{27}$

\section{Risk of bias within individual studies}

For each eligible trial and outcome, reviewers, following training and calibration exercises, use a revision of the Cochrane tool for assessing risk of bias in randomised trials (RoB 2.0 ${ }^{28}$ to rate trials as $(a)$ at low risk of bias; (b) some concerns, probably at low risk of bias; (c) some concerns, probably at high risk of bias; or $(d)$ high risk of bias, across the following domains: bias arising from the randomisation process; bias owing to departures from the intended intervention; bias from missing outcome data; bias in measurement of the outcome; bias in selection of the reported results, including deviations from the registered protocol; bias due to competing risks; and bias arising from early termination for benefit. We rate trials at high risk of bias overall if one or more domains were rated as (c) some concerns, probably high risk of bias or as (d) high risk of bias, and as low risk of bias overall if all domains were rated as $(b)$ some concerns, probably low risk of bias or $(a)$ low risk of bias. Reviewers resolve discrepancies by discussion and, when necessary, with adjudication by a third party.

\section{Data synthesis}

We performed bayesian random-effects network meta-analysis for outcomes with sufficient data, and synthesise all other outcomes using pairwise bayesian random-effects meta-analyses if there was only one comparison for a specific outcome. ${ }^{29}$

\section{Severity of illness}

For efficacy outcomes, we analysed patients with severe disease and non-severe disease separately. We changed our analysis plan after development of the initial protocol at the request of the linked WHO Guideline Development Group because several antiviral based therapies may have different effects in patients with non-severe disease than in patients with severe or critical disease. Severity was defined using the WHO severity scale. ${ }^{30}$ Non-severe disease includes patients who have oxygen saturation $>90 \%$ without supplementary oxygen, a respiratory rate of $<30$ breaths per minute, and without other clinical signs of severe respiratory distress.

\section{Summary measures}

We summarised the effect of interventions on dichotomous outcomes using odds ratios and their corresponding $95 \%$ credible interval (CI). For outcomes with extremely rare events, we summarised the effect of interventions using risk difference and 95\% CI. For continuous outcomes, specifically duration of hospital stay, we used the mean difference and corresponding 95\% CI because we expect similar durations across randomised trials. For time to symptom resolution, time to viral clearance, and duration of mechanical ventilation, we performed the analyses using ratio of means and corresponding $95 \% \mathrm{CI}$ before calculating the mean difference in days, as we expect substantial between-study. ${ }^{31}$ To mitigate highly implausible results or extreme imprecision, we limited our analyses to interventions with at least 100 participants or 20 events across studies. ${ }^{11}$

\section{Treatment nodes}

Treatments were grouped into nodes based on intervention, not dose or duration. We created network plots using the networkplot command of Stata version 15.1 (StataCorp, College Station, TX, USA). Thickness of lines between nodes and the size of nodes were based on the inverse variance of the direct comparison. ${ }^{32}$

\section{Statistical analysis}

We performed a random-effects bayesian meta-analysis using the bayesmeta package ${ }^{29}$ in RStudio version 3.5.3 (R Studio, Boston, MA, USA). As suggested in an empirical study, we used a plausible prior for the variance parameter and a uniform prior for the effect parameter. ${ }^{33}$ For outcomes where the median risk of an event in the control group was o (that is, TACO, TRALI, adverse events leading to discontinuation), we performed network meta-analysis with risk difference and fixed effects rather than odd ratios and random effects. Network meta-analysis was performed using the R package gemtc. We used three Markov chains with 100 ooo iterations after an initial burn-in of 10000 and a thinning of 10. Node splitting models were used to obtain indirect estimates and to assess local heterogeneity. ${ }^{34}$ We did not perform any adjustments for interventions with zero events. The R code used is available publicly at https://github.com/covid19lnma/covid19_lnma/.

\section{Certainty of the evidence}

We assessed the certainty of evidence using the grading of recommendations assessment, development, and evaluation (GRADE) approach, ${ }^{35-37}$ including specific guidance for network meta-analyses. ${ }^{14}$ Two methodologists with experience in using GRADE rated each domain for each comparison independently, resolving discrepancies by discussion. We rated the certainty for each comparison and outcome as high, moderate, low, or very low, taking into consideration risk of bias, inconsistency, indirectness, publication bias, imprecision, incoherence (differences between direct and indirect effect estimates), and intransitivity (differences in study characteristics that may modify the treatment effect in the direct comparisons that form the basis for the indirect estimate). ${ }^{1436}$ We used a minimally contextualised approach with a null effect threshold to rate the certainty that there is a benefit or a harm. ${ }^{38}$ When the point estimate is between the null effect and the minimally important difference, we rated the certainty that there is a trivial to no effect. ${ }^{38}$ In the absence of data from quantitative studies of patient values, the review team chose thresholds of small but important effects by consensus: $1 \%$ for mortality, $2 \%$ for mechanical ventilation, $1 \%$ for hospitalisation, 1 day for duration of hospitalisation, and $2 \%$ for all adverse effects. ${ }^{38}$

\section{Presentation and interpretation of results}

To facilitate interpretation of results of dichotomous outcomes, we calculated absolute effects per 1000 patients. To inform the risk of mortality in the standard care group in patients with severe or critical disease, we used data from the CDC on hospitalised patients with covid-19. ${ }^{39} 4^{\circ}$ For mechanical ventilation and duration of hospitalisation, we used baseline risks as reported from the International Severe Acute Respiratory and Emerging Infections 
Consortium (ISARIC) covid-19 database..$^{41}$ For all other outcomes, we used the median event rate in the standard care arm, weighing each study equally.

Results for all comparisons are also presented in an interactive format online (https://www.covid19lnma.com), which will be updated regularly as new data arises.

\section{Subgroup and sensitivity analysis}

We plan to conduct subgroup analyses based on high versus low risk of bias studies. Additionally, for convalescent plasma, we plan to perform subgroup analyses based on antibody titres and time of infusion relative to disease progression. We hypothesise that treatment with convalescent plasma will be more efficacious when transfusion occurs earlier in the disease course, and when plasma from patients with more severe illness is used. In the future, additional subgroup analyses may be conducted based on direction from the linked guidelines panels. When there is statistical evidence of a subgroup effect, we will assess its credibility using the Instrument to assess the Credibility of Effect Modification Analyses in randomised controlled trials and meta-analyses (ICEMAN) tool. 42

\section{Patient and public involvement}

Patients will be involved in the interpretation of results and the generation of parallel recommendations, as part of the BMJ Rapid Recommendations initiative in the future. So far, patients have not been involved for this first iteration.

\section{Results}

After screening 52350 titles and abstracts and 1029 full texts, 47 unique randomised controlled trials that evaluated antiviral antibody or cellular treatments were identified as of 21 July 2021 (fig 1). ${ }^{43-88} \mathrm{~A}$ table of excluded full texts is provided in the supplementary data on bmj.com. Searches of living evidence retrieval services identified 11 publications of eligible randomised trials, which were reconciled with our formal search strategy when necessary. ${ }^{22-254549566466-6875838688}$ Thirty randomised controlled trials were published in a peer reviewed journal, 16 were preprints, and one was an abstract. Thirty seven trials enrolled hospitalised patients, and 10 enrolled outpatients. All of the trials were registered and published in English. Fourteen different antiviral antibody or cellular treatments were evaluated for the treatment of covid-19: convalescent plasma (21 trials), intravenous immunoglobulin (IVIG) ( 5 trials), umbilical cord mesenchymal stem cells ( 5 trials), bamlanivimab (LY-CoV555; 4 trials), casirivimab-imdevimab (REGEN-COV; 4 trials), bamlanivimab-etesevimab (2 trials), control plasma (2 trials), peripheral blood non-haematopoietic enriched stem cells ( 2 trials), sotrovimab (1 trial), anti-SARS-CoV-2 IVIG (1 trial), therapeutic plasma exchange (1 trial), XAV-19 polyclonal antibody (1 trial), CT-P59 monoclonal antibody (1 trial), and INMoo5 polyclonal antibody (1 trial).

Table 1 presents the characteristics of the included studies. The supplementary data on bmj.com present additional study characteristics, outcome data, and risk of bias assessments for each study.
Table 1 | Characteristics of studies included in review of antibody and cellular therapies for treatment of covid-19. Values are numbers (percentages) of studies unless specified otherwise

\begin{tabular}{lc} 
Study characteristics & \\
Registered & $47(100 \%)$ \\
\hline Publication status: & $16(34 \%)$ \\
\hline Preprint & $30(64 \%)$ \\
\hline Published & $1(2 \%)$ \\
\hline Unpublished & $105.0(58-431)$ \\
\hline Median (IQR) No of patients & $16(34 \%)$ \\
\hline Country: & $5(11 \%)$ \\
\hline United States & $4(9 \%)$ \\
\hline India & $3(6 \%)$ \\
\hline Brazil & $3(6 \%)$ \\
\hline China & $10(21 \%)$ \\
\hline United Kingdom & $37(79 \%)$ \\
\hline Intensity of care: & $3(6 \%)$ \\
\hline Outpatient & $9(19 \%)$ \\
\hline Inpatient & \\
\hline ICU & \\
\hline Severity of illness: & \\
\hline Mild/moderate & \\
\hline Severe/critical & \\
\hline Median (IQR) percentage of patients receiving & \\
\hline mechanical ventilation & \\
\hline IQR = interquartile range. ICU = intensive care unit & \\
\hline
\end{tabular}

One randomised trial was identified after the data analysis: Dilogo $2021^{53}$ (registration No NCTo4457609), a trial of umbilical cord mesenchymal stromal cells versus placebo in 40 participants. It will be included in the next update.

Twelve preprints were subsequently published after peer review. The supplementary data present the differences between study preprint and peer-reviewed publications. Six studies had discrepancies in outcome reporting between the preprint and peer-reviewed publication. Five studies had discrepancies with patient baseline characteristics. Two studies had discrepancies in reporting that led to changes in risk of bias ratings. We found no substantiative differences for three studies.

\section{Risk of bias in included studies}

The supplementary data present the assessment of risk of bias of the included studies for each outcome. Twelve trials 5054566065677286 proved at low risk of bias for all domains. All other studies proved at probably high or high risk of bias for at least one domain.

\section{Effects of the interventions}

Figure 2 presents a summary of the effects of interventions on important efficacy and safety outcomes. The supplementary data include network plots and forest plots of pairwise meta-analyses for all outcomes, as well as detailed relative and absolute effect estimates and the certainty of evidence for all comparisons and outcomes.

\section{Non-severe disease}

Admission to hospital-Six trials including 8444 patients reported on admission to hospital (supplementary data). Patients randomised 
to four monoclonal antibody combinations had a lower risk of hospitalisation: casirivimab-imdevimab (odds ratio (OR) 0.29 (95\% CI 0.17 to 0.47 ); moderate certainty), bamlanivimab (OR 0.24 (0.06 to 0.86); low certainty), bamlanivimab-etesevimab (OR 0.31 (0.11 to 0.81 ); low certainty), and sotrovimab (OR 0.17 (0.04 to 0.57), low certainty) (fig 2). The certainty of all evidence was rated down due to imprecision (serious for casirivimab-imdevimab and very serious for the others because there were few events in the studies). The effect of CT-P59 monoclonal antibody was less certain (OR 0.48 (o.14 to 1.6o), low certainty).

Mortality-Eleven trials including 10683 patients reported mortality closest to 90 days (supplementary data). The risk of mortality is very low in patients with non-severe disease; as a result, no intervention was found to result in an important reduction in mortality. The effects of the interventions are:

casirivimab-imdevimab (OR 0.58 ( $95 \% \mathrm{CI} 0.26$ to 1.22 ); moderate certainty), bamlanivimab (OR 0.46 (o.01 to 27.79); low certainty), bamlanivimab-etesevimab (OR 0.05 (o.0o to 1.01); low certainty), sotrovimab (OR 0.33 (o.01 to 10.16), low certainty), CT-P59 (OR 0.51 (o.01 to 30.40); low certainty), and convalescent plasma (OR 0.83 (o.43 to 1.46); moderate certainty) (fig 2).

Mechanical ventilation-Six trials including 5775 patients reported need for mechanical ventilation (supplementary data). The risk of mechanical ventilation is very low in patients with non-severe disease. No intervention was found to result in an important reduction in mechanical ventilation: casirivimab-imdevimab (OR 0.21 (95\% CI 0.02 to 1.20); very low certainty), sotrovimab (OR 0.20 (o.01 to 5.07); very low certainty), and convalescent plasma (OR 0.71 (o.18 to 1.77 ); very low certainty).

Time to symptom resolution-Four trials including 5646 patients reported time to symptom resolution (supplementary data).

Casirivimab-imdevimab (ratio of means 0.72 ( $95 \%$ CI 0.58 to 0.92); moderate certainty) probably reduces duration of symptoms. The credible interval included no effect for bamlanivimab (ratio of means 0.92 ( $95 \%$ CI 0.64 to 1.32); low certainty), bamlanivimab-etesevimab (ratio of means 0.89 (o.68 to 1.16); moderate certainty), and CT-P59 (ratio of means 0.66 (0.42 to 1.05); moderate certainty).

Viral clearance at 7 days ( \pm 3 days)-Four trials including 1274 patients reported viral clearance (supplementary data). None of the interventions appeared to increase viral clearance at seven days: bamlanivimab (OR 0.90 ( $95 \% \mathrm{CI} 0.28$ to 3.06); low certainty), bamlanivimab-etesevimab (OR 1.31 (o.37 to 4.71); low certainty), CT-P59 (OR 1.67 (0.53 to 5.21); low certainty), and convalescent plasma (OR 2.05 (0.92 to 5.31); very low certainty).

Time to viral clearance-Two trials including 877 patients reported time to viral clearance (supplementary data). None of the monoclonal antibodies tested appeared to reduce time to viral clearance, as measured by nasopharyngeal PCR: bamlanivimab (ratio of means 1.01 (95\% CI 0.39 to 2.69); low certainty),

bamlanivimab-etesevimab (ratio of means 0.88 (0.34 to 2.36); low certainty), and CT-P59 (ratio of means 0.95 (0.35 to 2.56); low certainty).

\section{Severe disease}

Mortality-Nineteen trials including 24229 patients reported mortality (supplementary data). None of the interventions tested appeared to reduce mortality: casirivimab-imdevimab (OR 0.94 ( $95 \%$ CI 0.58 to 1.52); very low certainty), convalescent plasma (OR 0.92 (0.70 to 1.12); low certainty), and IVIg (OR 0.70 (0.39 to 1.16); very low certainty). The RECOVERY trial found a credible subgroup effect suggesting that casirivimab-imdevimab may reduce mortality in patients without detectable antibodies at the time of randomisation. ${ }^{63}$

Mechanical ventilation-Eight trials including 840 patients reported need for mechanical ventilation (supplementary data). Neither convalescent plasma (OR 0.92 ( $95 \%$ CI 0.46 to 1.68); very low certainty) nor IVIg (OR 0.67 (0.29 to 1.45); very low certainty) reduced mechanical ventilation.

Duration of hospitalisation-Twenty trials including 24529 patients reported duration of hospitalisation (supplementary data). Neither convalescent plasma (mean difference -0.7 days ( $95 \% \mathrm{CI}-2.3$ to 1.0); low certainty) nor IVIg (mean difference -2.1 days ( -5.8 to 1.6); very low certainty) reduced duration of hospitalisation.

Duration of mechanical ventilation-No interventions included at least 100 patients and thus no network meta-analysis was conducted.

Ventilator-free days-Three trials including 2857 patients reported ventilator-free days (supplementary data). Convalescent plasma may not affect ventilator-free days (mean difference -0.7 days ( $95 \%$ CI -1.8 to 0.4 ); low certainty).

Time to symptom resolution-One trial including 333 patients reported time to symptom resolution. ${ }^{89}$ The study found that convalescent plasma may not affect time to complete resolution of physical function (subhazard ratio 0.89 ( $95 \% \mathrm{CI} 0.66$ to 1.18$)$ ) or time to improvement of two categories in the WHO ordinal scale (hazard ratio 1.00 (0.76 to 1.32$)$ ).

ICU length of stay-Two trials including 914 patients reported ICU length of stay. One of these trials analysed at least 100 patients in each arm. ${ }^{64}$ Convalescent plasma may not affect ICU length of stay (mean difference 0.6 days ( $95 \% \mathrm{CI}-0.44$ to 1.64); low certainty).

\section{Adverse effects}

Adverse effects leading to intervention discontinuation-Ten trials including 7895 patients reported adverse effects leading to treatment discontinuation (supplementary data). Certainty was very low for convalescent plasma and IVIg. Bamlanivimab (RD -2 per $1000(95 \%$ $\mathrm{CI}-13$ to 9); moderate certainty) and casirivimab-imdevimab (RD -2 per 1000 ( -4 to o); moderate certainty) probably do not result in an important increase in adverse effects leading to discontinuation.

Infusion reactions-Nineteen trials including 31708 patients reported infusion reactions (supplementary data). Convalescent plasma probably causes infusion reactions, but the absolute risk is very low (OR 3.25 (95\% CI 1.27 to 9.30); RD 6 per 1000 (1 to 18); moderate certainty). The credible interval included no effect for the other interventions: bamlanivimab (OR 1.84 ( $95 \%$ CI 0.74 to 5.26 ); moderate certainty of no important increase),

bamlanivimab-etesevimab (OR 1.68 (0.17 to 12.94); low certainty), casirivimab-imdevimab (OR 2.41 (o.57 to 13.07); low certainty), CT-P59 (OR 0.20 (o.0o to 3.67); low certainty), and sotrovimab (OR 0.39 (o.01 to 6.49); low certainty).

Transfusion-associated circulatory overload (TACO)-Four trials including 1442 patients reported TACO (supplementary data). The risk of TACO with convalescent plasma may be small ( $R \mathrm{R}_{5}$ per 1000 ( $95 \%$ CI -1 to 12 ); low certainty).

Transfusion-related acute lung injury (TRALI)-Four trials including 1365 patients reported TRALI (supplementary data). The risk of TRALI from convalescent plasma may be small (RD no difference per 1000 ( $95 \%$ CI -5 to 6$)$; low certainty). 


\section{Discussion}

Our living systematic review and network meta-analysis provides an overview of all trials administering blood products for treatment of covid-19 up to 21 July 2021. Currently, trials have only focused on treatment of covid-19 with the monoclonal antibodies

bamlanivimab, bamlanivimab-etesevimab, casirivimab-imdevimab, CT-P59, and sotrovimab, as well as convalescent plasma and intravenous immunoglobulin (IVIg).

Monoclonal antibodies appear to be more effective in patients with non-severe disease than in patients with severe disease. In patients with non-severe disease, patients randomised to any of the monoclonal antibodies had a lower risk of hospitalisation than those randomised to placebo. However, only casirivimab-imdevimab had moderate certainty for this outcome. The impact on other patient-important outcomes was less certain because few patients with non-severe disease died or required mechanical ventilation.

An alternative view of this evidence is that there is at least moderate certainty that antiviral monoclonal antibodies do not confer an important reduction in mortality or mechanical ventilation among all patients with non-severe covid-19 because the risk of death is very low regardless of the interventions used.

Our review did not find evidence that any of the blood products or antiviral antibodies had an impact on outcomes in patients with severe or critical covid-19. However, a subgroup analysis from the RECOVERY trial opens the possibility that antiviral monoclonal antibodies may reduce mortality in patients who do not have detectable antibodies against the SARS-CoV-2 spike protein. ${ }^{63}$ The subgroup effect is of moderate credibility according to ICEMAN criteria. ${ }^{42}$

Operationalising this subgroup effect is difficult, given that rapid antibody testing is not currently widely available. If the subgroup effect is true, it is possible that casirivimab-imdevimab may increase mortality in patients with severe covid-19 who have detectable antibody response. The linked WHO guideline panel therefore made a recommendation against using casirivimab-imdevimab in patients with severe covid-19 and unknown serostatus. ${ }^{16}$

The randomised trials included in our review generally did not enrol patients with contemporary SARS-COV-2 variants, including the delta variant. Antiviral antibody-based therapies may be less effective against some newer variants. ${ }^{\circ 0}$ The B.1.617 variant, for example, is resistant to bamlanivimab, and several health authorities have recommended against its use as monotherapy-thus prompting the combination product with etesevimab. ${ }^{91}$

Our review did not find evidence that convalescent plasma confers any benefit to patients with covid-19 of any severity. Evidence was consistent between trials, except one, that limited donors to those with higher neutralising titres and enrolled high risk patients with non-severe disease. ${ }^{71}$ This finding has not yet been replicated and is inconsistent with the body of evidence on convalescent plasma; therefore whether or not high titre convalescent plasma confers any benefit remains uncertain.

We are aware of a living Cochrane review that addresses the use of convalescent plasma or hyperimmune immunoglobin for patients with covid-19..$^{92}$ The results of their meta-analysis-though based on only nine randomised trials-are consistent with our conclusions: currently, there is uncertainty about the efficacy of convalescent plasma for covid-19. One recent systematic review on interventions in outpatients with covid-19 included nine trials and concluded that bamlanivimab-etesevimab probably reduces progression to severe disease, and insufficient information about other interventions. ${ }^{93}$
To our knowledge, our review is the most comprehensive published to date on this topic.

\section{Strengths and limitations of this review}

Our living systematic review is conducted by a multidisciplinary team of clinical and methodological experts who have undergone extensive training and calibration exercises for each part of the review process. We utilised a comprehensive literature search without any restrictions on language or publication status, explicit eligibility criteria, and limited meta-analysis of interventions that were randomised to at least 100 patients (or had $\geq 20$ events) to avoid spurious or imprecise findings with network meta-analysis. We used the GRADE approach to rate the certainty of the evidence.

With respect to limitations, our prespecified thresholds for imprecision were not based on empirical data and are determined based on consensus within the review team. Thus, judgments about the certainty of the evidence may differ if people have different thresholds for what they consider an important effect.

The main limitation of the evidence is lack of blinding in most of the included trials of blood products, including convalescent plasma, and the possible differential administration of cointerventions and supportive therapies between the intervention and standard care arms. Thus, consistent with GRADE guidance, we rated down the certainty of the evidence due to risk of bias for all affected outcomes. 94

Given that ours is a living systematic review, the risk of publication bias may be amplified, since trials with more positive or promising results are likely to be published sooner than those with insignificant findings.

We will periodically update this review as we identify more eligible trials through our systematic search and perform network meta-analysis if data permits. This review will be accompanied by an interactive infographic, and updated results and additional study data will be available on our website https://www.covid19lnma.com.

\section{Conclusions}

In patients with non-severe covid-19, the antiviral monoclonal antibodies casirivimab-imdevimab probably reduce risk of hospitalisation; bamlanivimab, bamlanivimab-etesevimab, and sotrovimab may reduce hospitalisation. Casirivimab-imdevimab may reduce the risk of mortality in patients with severe covid-19 who do not have detectable antibodies to the SARS-CoV-2 spike protein, but casirivimab-imdevimab and all other interventions do not appear to have any impact when given to all patients with severe covid-19. Low rates of adverse events leading to discontinuation, transfusion-related acute lung injury (TRALI), and transfusion-associated circulatory overload (TACO) make it difficult to make conclusions about the safety of antiviral monoclonal antibodies and convalescent plasma. Additional high quality data are needed to evaluate the efficacy and safety of antiviral antibodies and blood products for the treatment of covid-19.

\section{What is already known on this topic}

- Effective and safe interventions for coronavirus disease 2019 (covid-19) remain elusive, especially in patients with non-severe disease

\section{What this study adds}

- This living systematic review and network meta-analysis provides a comprehensive overview the evidence for antibody and cellular therapies used for treatment of covid-19 to 21 July 2021 
- Casirivimab-imdevimab probably reduces hospitalisation in patients with non-severe covid-19

- Casirivimab-imdevimab may reduce mortality in patients with severe or critical disease who do not have detectable antibodies

- Bamlanivimab, bamlanivimab-etesevimab, and sotrovimab may reduce hospitalisation

- Convalescent plasma and intravenous immunoglobulins may not have any important impact in patients with covid-19

\section{AUTHOR AFFILIATIONS}

1 Department of Health Research Methods, Evidence, and Impact, McMaster University, Hamilton, ON L8S 4L8, Canada

Department of Medicine, McMaster University, Hamilton, ON, Canada

Servicio de Clinica Médica del Hospital Alemán, Buenos Aires, Argentina

4 Evidence Based Social Science Research Center, School of Public Health, Lanzhou University, Lanzhou, Gansu, China

Department of Preventive Medicine, College of Medicine, Chosun University, Gwangju, Republic of Korea

Division of General Internal Medicine \& Division of Clinical Epidemiology, University Hospitals of Geneva, Geneva, Switzerland

Epistemonikos Foundation, Santiago, Chile

Department of Anesthesia, McMaster University, Hamilton, ON, Canada

9 Department of Medicine, University of Calgary, Calgary, AB, Canada

Medical school, University of Toronto, Toronto, ON, Canada

Ted Rogers Center for Heart Research, University Health Network, Toronto, ON, Canada

12

Wolfson Palliative Care Research Centre, Hull York Medical School, Hull, UK

Department of Medicine and Centre de recherche du CHU de Sherbrooke, Sherbrooke, Quebec, Canada

Department of Pediatrics, Faculty of Medicine, University of British Columbia, Vancouver

Department of Medicine, University of Kansas Medical Center, Kansas City, MO, USA

Institute of Health and Society, University of Oslo, Oslo, Norway

Department of Nephrology and Hypertension, University Medical Center Utrecht, Utrecht, Netherlands

Julius Center for Health Sciences and Primary Care, University Medical Center Utrecht, Utrecht University, Utrecht, Netherlands

Joint first authors

Contributors: RACS, JJB, JDM, EK, AQ, and DZ contributed equally to the systematic review and are joint first authors. RACS, JJB, EK, JDM, AQ, SM, DZ, LG, and RB-P were the core team leading the systematic review. JJB, RC, RWMV, SM, YW, AD, TD, Al, CS, AV-G, and MG identified and selected the studies. DZ, EK, EC, RWMV, AA, AK, YW, KH, HP-H, MAH, CF, AS, and MG collected the data. AQ, AK, LG, and GHG analysed the data. RB-P, FF, HP-H, MG, Al, AM, RAM, TD, and DC assessed the certainty of the evidence SLM, SM, FL, BR, TA, POV, GHG, ML, DA, and GR provided advice at different stages. RACS, RB-P, and GHG drafted the manuscript.

All authors approved the final version of the manuscript. RACS is the guarantor. The corresponding author attests that all listed authors meet authorship criteria and that no others meeting the criteria have been omitted.

Funding: This study was supported by the Canadian Institutes of Health Research (grant CIHR-IRSC:0579001321). The funders had no role in considering the study design or in the collection, analysis, interpretation of data, writing of the report, or decision to submit the article for publication.
Competing interests: All authors have completed the ICMJE uniform disclosure form at www.icmje.org/coi_disclosure.pdf and declare: support from the Canadian Institutes of Health Research for the submitted work; ML reports personal fees and non-financial support from Sanofi, grants and personal fees from Seqirus, personal fees from Pfizer, and personal fees from Medicago outside the submitted work, and is a co-investigator on ACT randomised trial of covid-19 therapy; LG reports grants from Ministry of Science and Technology of China outside the submitted work.

RACS affirms that this manuscript is an honest, accurate, and transparent account of the study being reported; that no important aspects of the study have been omitted; and that any discrepancies from the study as planned have been explained.

Dissemination to participants and related patient and public communities: The infographic and MAGICapp decision aids (available at www.magicapp.org/) were created to facilitate conversations between healthcare providers and patients or their surrogates. The MAGICapp decision aids were co-created with people who have lived experience of covid-19.

Provenance and peer review: Not commissioned; externally peer reviewed.

Ethical approval: Not applicable. All the work was developed using published data.

Data sharing: No additional data available

1 Johns Hopkins University. Coronavirus resource center. 2020. https://coronavirus.jhu.edu/map.html.

2 Cytel. Global coronavirus COVID-19 clinical trial tracker. 2020. https://www.covid19-trials.com/.

3 Mair-Jenkins J, Saavedra-Campos M, Baillie JK, etalConvalescent Plasma Study Group. The effectiveness of convalescent plasma and hyperimmune immunoglobulin for the treatment of severe acute respiratory infections of viral etiology: a systematic review and exploratory meta-analysis. J Infect Dis 2015;211:80-90. . doi: 10.1093/infdis/jiu396 pmid: 25030060

4 Devasenapathy $\mathrm{N}$, Ye Z, Loeb M, etal. Efficacy and safety of convalescent plasma for severe COVID-19 based on evidence in other severe respiratory viral infections: a systematic review and meta-analysis. CMA/2020:192:E745-55 . doi: 10.1503/cmaj.200642 pmid: 32444482

5 Bozzo J, Jorquera Jl. Use of human immunoglobulins as an anti-infective treatment: the experience so far and their possible re-emerging role. Expert Rev Anti Infect Ther 2017;15:585-604 . doi: 10.1080/14787210.2017.1328278 pmid: 28480779

6 van Griensven J, Edwards T, de Lamballerie X, etalEbola-Tx Consortium. Evaluation of convalescent plasma for Ebola virus disease in Guinea. N Engl J Med 2016;374:33-42. doi: 10.1056/NEJMoa1511812 pmid: 26735992

7 US Food \& Drug Administration. Convalescent plasma COVID-19 letter of authorization. 2021. https://www.fda.gov/media/141477/download.

8 Looney RJ, Huggins J. Use of intravenous immunoglobulin G (IVIG). Best Pract Res Clin Haemato 2006;19:3-25. . doi: 10.1016/j.beha.2005.01.032 pmid: 16377538

9 Taylor PC, Adams AC, Hufford MM, de la Torre I, Winthrop K, Gottlieb RL. Neutralizing monoclonal antibodies for treatment of COVID-19. Nat Rev Immunol 2021;21:382-93. doi: 10.1038/s41577-021-00542-x pmid: 33875867

10 Djulbegovic B, Guyatt G. Evidence-based medicine in times of crisis. / Clin Epidemiol 2020;126:164-6. . doi: 10.1016/j.jclinepi.2020.07.002 pmid: 32659364

11 Siemieniuk RA, Bartoszko IJ, Ge L, etal. Drug treatments for covid-19: living systematic review and network meta-analysis. BMJ2020;370:m2980. . doi: 10.1136/bmj.m2980 pmid: 32732190

12 Bartoszko JJ, Siemieniuk RAC, Kum E, etal. Prophylaxis against covid-19: living systematic review and network meta-analysis. BMJ2021;373:n949. . doi: 10.1136/bmj.n949 pmid: 33903131

13 Vandvik PO, Brignardello-Petersen R, Guyatt GH. Living cumulative network meta-analysis to reduce waste in research: A paradigmatic shift for systematic reviews?BMC Med 2016;14:59. . doi: 10.1186/s12916-016-0596-4 pmid: 27025849

14 Puhan MA, Schünemann HJ, Murad MH, etalGRADE Working Group. A GRADE Working Group approach for rating the quality of treatment effect estimates from network meta-analysis. $B M$ 2014;349:g5630. . doi: 10.1136/bmj.g5630 pmid: 25252733

15 Siemieniuk RA, Agoritsas T, Macdonald H, Guyatt GH, Brandt L, Vandvik PO. Introduction to BM Rapid Recommendations. BM/2016;354:15191. . doi: 10.1136/bmj.i5191 pmid: 27680768

16 Lamontagne F, Agoritsas T, Siemieniuk R, etal. A living WHO guideline on drugs to prevent Covid-19. BMJ2021;372:n526. . doi: 10.1136/bmj.n526 pmid: 33649077

17 World Health Organization. Therapeutics and COVID-19: living guideline. 2021 https://www.who.int/publications/i/item/WHO-2019-nCoV-therapeutics-2021.2.

18 Moher D, Liberati A, Tetzlaff J, Altman DGPRISMA Group. Preferred reporting items for systematic reviews and meta-analyses: the PRISMA statement. BM/2009;339:b2535 doi: 10.1136/bmj.b2535 pmid: 1962255

19 Page MJ, McKenzie JE, Bossuyt PM, etal. The PRISMA 2020 statement: an updated guideline for reporting systematic reviews. BM/2021;372:n71 . doi: 10.1136/bmi.n71 pmid: 33782057

20 Hutton B, Salanti G, Caldwell DM, etal. The PRISMA extension statement for reporting of systematic reviews incorporating network meta-analyses of health care interventions: checklist and explanations. Ann Intern Med2015;162:777-84 . doi: 10.7326/M14-2385 pmid: 26030634

21 Elliott JH, Synnot A, Turner T, etalLiving Systematic Review Network. Living systematic review: 1. Introduction-the why, what, when, and how. J Clin Epidemiol 2017;91:23-30. . doi: 10.1016/j.jclinepi.2017.08.010 pmid: 28912002

22 Centers for Disease Control and Prevention. COVID-19 research articles downloadable database. 2020. https://www.cdc.gov/library/researchguides/2019novelcoronavirus/researcharticles.html. 
23 Marshall II, Noel-Storr A, Kuiper J, Thomas J, Wallace BC. Machine learning for identifying randomized controlled trials: an evaluation and practitioner's guide. Res Synth Methods 2018;9:602-14. . doi: 10.1002/jrsm.1287 pmid: 29314757

24 Epistemonikos Foundation. Living evidence repository for COVID-19. 2020. https://www.epistemonikos.c//living-evidence/.

25 Norwegian Institute of Public Health. NIPH systematic and living map on COVID-19 evidence. 2020. https://www.nornesk.no/forskningskart/NIPH_mainMap.html.

26 CADTH Covid-19 Pandemic. Convalescent plasma therapy for the treatment of COVID-19: a review of clinical effectiveness. 2020. https://covid.cadth.ca/treatment/convalescent-plasmatherapy-for-the-treatment-of-covid-19-a-review-of-clinical-effectiveness-2/.

27 World Health Organization. Criteria for releasing COVID-19 patients from isolation: Scientific Brief. 2020. https://www.who.int/publications/i/item/criteria-for-releasing-covid-19-patients-from-isolation.

28 Sterne JAC, Savović J, Page MJ, etal. RoB 2: a revised tool for assessing risk of bias in randomised trials. BMJ 2019;366:14898 . doi: 10.1136/bmj.14898 pmid: 31462531

29 Rover C. Bayesian random-effects meta-analysis using the bayesmeta R package. J Stat Softw 2017;93:1-51. doi: 10.18637/jss.v093.106

30 Rochwerg B, Agarwal A, Siemieniuk RA, etal. A living WHO guideline on drugs for covid-19. BM 2020;370:m3379. . doi: 10.1136/bmj.m3379 pmid: 32887691

31 Friedrich JO, Adhikari NK, Beyene J. Ratio of means for analyzing continuous outcomes in meta-analysis performed as well as mean difference methods. J Clin Epidemiol 2011;64:556-64. . doi: 10.1016/j.jclinepi.2010.09.016 pmid: 21447428

32 Chaimani A, Higgins JP, Mavridis D, Spyridonos P, Salanti G. Graphical tools for network meta-analysis in STATA. PLOS One 2013;8:e76654. doi: 10.1371/journal.pone.0076654 pmid: 24098547

33 Turner RM, Jackson D, Wei Y, Thompson SG, Higgins JP. Predictive distributions for between-study heterogeneity and simple methods for their application in Bayesian meta-analysis. Stat Med 2015;34:984-98. . doi: 10.1002/sim.6381 pmid: 25475839

34 van Valkenhoef G, Dias S, Ades AE, Welton NJ. Automated generation of node-splitting models for assessment of inconsistency in network meta-analysis. Res Synth Methods 2016;7:80-93. doi: 10.1002/jrsm.1167 pmid: 26461181

35 Atkins D, Best D, Briss PA, etalGRADE Working Group. Grading quality of evidence and strength of recommendations. BM/2004;328:1490. . doi: 10.1136/bmi.328.7454.1490 pmid: 15205295

36 Brignardello-Petersen R, Bonner A, Alexander PE, etalGRADE Working Group. Advances in the GRADE approach to rate the certainty in estimates from a network meta-analysis. J Clin Epidemiol 2018;93:36-44. . doi: 10.1016/j.jclinepi.2017.10.005 pmid: 29051107

37 Brignardello-Petersen R, Mustafa RA, Siemieniuk RAC, etalGRADE Working Group. GRADE approach to rate the certainty from a network meta-analysis: addressing incoherence. J Clin Epidemio/2019;108:77-85. . doi: 10.1016/j.jclinepi.2018.11.025 pmid: 30529648

38 Hultcrantz M, Rind D, Akl EA, etal. The GRADE Working Group clarifies the construct of certainty of evidence. J Clin Epidemiol2017;87:4-13. . doi: 10.1016/j.jclinepi.2017.05.006 pmid: 28529184

39 Centers for Disease Control and Prevention. COVIDView. A weekly surveillance summary of U.S COVID-19 activity. 2020. https://www.cdc.gov/coronavirus/2019-ncov/covid-data/covidview/index.html.

40 Centers for Disease Control and Prevention. Daily updates of totals by week and state: provisional death counts for coronavirus disease 2019 (COVID-19). 2020. .https://www.cdc.gov/nchs/nvss/vsrr/COVID19/index.htm.

41 Pritchard M, Dankwa E, Hall M, etal. ISARIC COVID-19 Clinical Data Report: 4 October 2020.medRxiv 2020:2020.07.17.20155218. doi: 10.1101/2020.07.17.20155218

42 Schandelmaier S, Briel M, Varadhan R, etal. Development of the Instrument to assess the Credibility of Effect Modification Analyses (ICEMAN) in randomized controlled trials and meta-analyses. CMA/2020;192:E901-6. . doi: 10.1503/cmaj.200077 pmid: 32778601

43 Agarwal A, Mukherjee A, Kumar G, etal. Convalescent plasma in the management of moderate COVID-19 in India: An open-label parallel-arm phase II multicentre randomized controlled tria (PLACID Trial) (preprint).medRxiv 2020:2020.09.03.20187252.

44 Ali S, Uddin SM, Shalim E, etal. Hyperimmune anti-COVID-19 IVIG (C-IVIG) treatment in severe and critical COVID-19 patients: A phase I/II randomized control trial. EClinicalMedicine 2021;36:100926. . doi: 10.1016/j.eclinm.2021.100926 pmid: 34109306

45 AlQahtani M, Abdulrahman A, Almadani A, etal. Randomized controlled trial of convalescent plasma therapy against standard therapy in patients with severe COVID-19 disease. Sci Rep 2021;11:9927. . doi: 10.1038/s41598-021-89444-5 pmid: 33976287

46 Avendano-Sola C, Ramos-Martinez A, Munez-Rubio E, etal. Convalescent plasma for COVID-19: A multicenter, randomized clinical trial (preprint).medRxiv 2020:2020.08.26.20182444. doi: 10.1101/2020.08.26.20182444

47 Bajpai M, Kumar S, Maheshwari A, etal. Efficacy of convalescent plasma therapy compared to fresh frozen plasma in severely ill COVID-19 patients: a pilot randomized controlled trial.medRxiv 2020:2020.10.25.20219337. doi: 10.1101/2020.10.25.20219337

48 Balcells ME, Rojas L, Le Corre N, etal. Early versus deferred anti-SARS-CoV-2 convalescent plasma in patients admitted for COVID-19: A randomized phase II clinical trial. PLoS Med 2021;18:e1003415. . doi: 10.1371/journal.pmed.1003415 pmid: 33657114

49 Bandopadhyay P, D'Rozario R, Lahiri A, etal. Nature and dimensions of the cytokine storm and its attenuation by convalescent plasma in severe COVID-19.medRxiv2020:2020.09.21.20199109. doi: 10.1101/2020.09.21.20199109
50 Bennett-Guerrero E, Romeiser LL, Talbot LR, etalStony Brook Medicine COVID Plasma Trial Group. Severe acute respiratory syndrome coronavirus 2 convalescent plasma versus standard plasma in coronavirus disease 2019 infected hospitalized patients in New York: a double-blind randomized trial. Crit Care Med2021;49:1015-25. doi: 10.1097/ccm.0000000000005066. pmid: 33870923

51 Chen P, Nirula A, Heller B, etalBLAZE-1 Investigators. SARS-CoV-2 neutralizing antibody LY-CoV555 in outpatients with Covid-19. N Engl J Med 2021;384:229-37. doi: 10.1056/NEJMoa2029849 pmid: 33113295

52 Chew K, Moser C, Daar E. Symptom outcome measures for outpatient Covid-19 phase 3 treatment trials. Abstract. Conference on Retroviruses and Opportunistic Infections 2021. https://www.croiconference.org/abstract/symptom-outcome-measures-for-outpatient-covid-19phase-3-treatment-trials/.

53 Dilogo $\mathrm{IH}$, Aditianingsih D, Sugiarto A, etal. Umbilical cord mesenchymal stromal cells as critical COVID-19 adjuvant therapy: A randomized controlled trial. Stem Cells TransI Med 2021;10:1279-87. . doi: 10.1002/sctm.21-0046 pmid: 34102020

54 Dougan M, Nirula A, Azizad M, etalBLAZE-1 Investigators. Bamlanivimab plus etesevimab in mild or moderate Covid-19. N Engl J Med 2021; . doi: 10.1056/NEJMoa2102685 pmid: 34260849

55 Faqihi F, Alharthy A, Abdulaziz S, etal. Therapeutic plasma exchange in patients with life-threatening COVID-19: a randomised controlled clinical trial. Int I Antimicrob Agents 2021;57:106334. . doi: 10.1016/j.jiantimicag.2021.106334 pmid: 33838224

56 Gaborit B, Dailly E, Vanhove B, etalPOLYCOR Trial Group. Pharmacokinetics and safety of XAV-19, a swine glyco-humanized polyclonal anti-SARS-CoV-2 antibody, for COVID-19-related moderate pneumonia: a randomized, double-blind, placebo-controlled, phase lla study. Antimicrob Agents Chemother 2021;65:e0123721. . doi: 10.1128/AAC.01237-21 pmid: 34181475

57 Gharbharan A, Jordans CCE, GeurtsvanKessel C, etal. Effects of potent neutralizing antibodies from convalescent plasma in patients hospitalized for severe SARS-CoV-2 infection. Nat Commun 2021;12:3189. . doi: 10.1038/s41467-021-23469-2 pmid: 34045486

58 Gharebaghi N, Nejadrahim R, Mousavi SJ, Sadat-Ebrahimi SR, Hajizadeh R. The use of intravenous immunoglobulin gamma for the treatment of severe coronavirus disease 2019: a randomized placebo-controlled double-blind clinical trial. BMC Infect Dis 2020;20:786. doi: 10.1186/s12879-020-05507-4 pmid: 33087047

59 Gonzalez JLB, González Gámez M. Mendoza Enciso EA, etal. Efficacy and safety of convalescent plasma and intravenous immunoglobulin in critically ill COVID-19 patients. A controlled clinical trial.medRxiv 2021:2021.03.28.21254507. doi: 10.1101/2021.03.28.21254507

60 Gottlieb RL, Nirula A, Chen P, etal. Effect of bamlanivimab as monotherapy or in combination with etesevimab on viral load in patients with mild to moderate COVID-19: a randomized clinical trial. JAMA 2021;325:632-44. . doi: 10.1001/jama.2021.0202 pmid: 33475701

61 Lundgren JD, Grund B, Barkauskas CE, etalACTIV-3/TICO LY-CoV555 Study Group. A neutralizing monoclonal antibody for hospitalized patients with Covid-19. N Engl J Med 2021;384:905-14 . doi: 10.1056/NEJMoa2033130 pmid: 33356051

62 RECOVERY Collaborative Group. Convalescent plasma in patients admitted to hospital with COVID-19 (RECOVERY): a randomised controlled, open-label, platform trial. Lancet 2021;397:2049-59. . doi: 10.1016/S0140-6736(21)00897-7 pmid: 34000257

63 RECOVERY Collaborative GroupHorby PW, Mafham M, etal. Casirivimab and imdevimab in patients admitted to hospital with COVID-19 (RECOVERY): a randomised, controlled, open-label, platform trial.medRxiv 2021:2021.06.15.21258542. doi: 10.1101/2021.06.15.21258542

64 The CONCOR-1 Study Group CONCOR-1 writing committeeBégin P, etal. Convalescent plasma for hospitalized patients with COVID-19 and the effect of plasma antibodies: a randomized controlled, open-label trial.medRxiv2021:2021.06.29.21259427. doi: 10.1101/2021.06.29.21259427

65 Gupta A, Gonzalez-Rojas Y, Juarez E, etal. Early Covid-19 treatment with SARS-CoV-2 neutralizing antibody sotrovimab. medRxiv 2021:2021.05.27.21257096. doi: 10.1101/2021.05.27.21257096

66 The REMAP-CAP InvestigatorsEstcourt LJ. Convalescent plasma in critically ill patients with Covid-19.medRxiv 2021:2021.06.11.21258760. doi: 10.1101/2021.06.11.21258760

67 Joong Sik E, Michael I, Anca S-C, etal. Efficacy and safety of CT-P59 plus standard of care: a phase 2/3 randomized, double-blind, placebo-controlled trial in outpatients with mild-to-moderate SARS-CoV-2 infection.Research Square 2021doi: 10.21203/rs.3.rs-296518/v1

68 Körper S, Weiss M, Zickler D, etal. High dose convalescent plasma in COVID-19: results from the randomized trial CAPSID.medRxiv2021:2021.05.10.21256192. doi: 10.1101/2021.05.10.21256192

69 Lanzoni G, Linetsky E, Correa D, etal. Umbilical cord mesenchymal stem cells for COVID-19 acute respiratory distress syndrome: A double-blind, phase 1/2a, randomized controlled trial. Stem Cells Transl Med 2021;10:660-73. . doi: 10.1002/sctm.20-0472 pmid: 33400390

70 Li L, Zhang W, Hu Y, etal. Effect of convalescent plasma therapy on time to clinical improvement in patients with severe and life-threatening COVID-19: a randomized clinical trial. JAMA 2020;324:460-70. . doi: 10.1001/jama.2020.10044 pmid: 32492084

71 Libster R, Pérez Marc G, Wappner D, etalFundación INFANT-COVID-19 Group. Early high-titer plasma therapy to prevent severe Covid-19 in older adults. N Engl J Med 2021;384:610-8. doi: 10.1056/NEJMoa2033700 pmid: 33406353

72 Lopardo G, Belloso WH, Nannini E, etallNM005 Study Group. RBD-specific polyclonal F(ab`)2 fragments of equine antibodies in patients with moderate to severe COVID-19 disease: A randomized, multicenter, double-blind, placebo-controlled, adaptive phase $2 / 3$ clinical trial. EClinicalMedicine 2021;34:100843. . doi: 10.1016/j.eclinm.2021.100843 pmid: 33870149

73 O'Donnell MR, Grinsztejn B, Cummings MJ, etal. A randomized double-blind controlled trial of convalescent plasma in adults with severe COVID-19. J Clin Invest 2021;131:150646. doi: 10.1172/JCl150646 pmid: 33974559 
74 O'Brien MP, Forleo-Neto E, Sarkar N, etal. Subcutaneous REGEN-COV antibody combination in early SARS-CoV-2 infection.medRxiv 2021:2021.06.14.21258569. doi: 10.1101/2021.06.14.21258569

75 Ossama HS, Mohamed HSA. Efficacy and safety of transfusing plasma from COVID-19 survivors to COVID-19 victims with severe illness. A double-blinded controlled preliminary study. Egypt J Anaesth 2020;36:264-72. doi: 10.1080/11101849.2020.1842087 .

76 Pouladzadeh M, Safdarian M, Eshghi P, etal. A randomized clinical trial evaluating the immunomodulatory effect of convalescent plasma on COVID-19-related cytokine storm. Intern Emerg Med2021;1-11. doi: 10.1007/s11739-021-02734-8. pmid: 33837906

77 Raman RS, Bhagwan Barge V, Anil Kumar D, etal. A phase II safety and efficacy study on prognosis of moderate pneumonia in coronavirus disease 2019 patients with regular intravenous immunoglobulin therapy. J Infect Dis 2021;223:1538-43. . doi: 10.1093/infdis/jiab098 pmid: 33585890

78 Ray Y, Paul SR, Bandopadhyay P, etal. Clinical and immunological benefits of convalescent plasma therapy in severe COVID-19: insights from a single center open label randomised control trial.medRxiv 2020:2020.11.25.20237883. doi: 10.1101/2020.11.25.20237883

79 Sakoulas G, Geriak M, Kullar R, etal. Intravenous immunoglobulin plus methylprednisolone mitigate respiratory morbidity in coronavirus disease 2019. Crit Care Explor 2020;2:e0280. . doi: 10.1097/CCE.0000000000000280 pmid: 33225306

80 Sekine L, Arns B, Fabro BR, etalPLACOVID Study Group. Convalescent plasma for COVID-19 in hospitalised patients: an open-label, randomised clinical trial. Eur Respir /2021;2101471. . doi: 10.1183/13993003.01471-2021 pmid: 34244316

81 Shi L, Huang H, Lu X, etal. Effect of human umbilical cord-derived mesenchymal stem cells on lung damage in severe COVID-19 patients: a randomized, double-blind, placebo-controlled phase 2 trial. Signal Transduct Target Ther 2021;6:58. doi: 10.1038/s41392-021-00488-5 pmid: 33568628

82 Shu L, Niu C, Li R, etal. Treatment of severe COVID-19 with human umbilical cord mesenchymal stem cells. Stem Cell Res Ther2020;11:361. . doi: 10.1186/s13287-020-01875-5 pmid: 32811531

83 Simonovich VA, Burgos Pratx LD, Scibona P, etalPlasmAr Study Group. A Randomized trial of convalescent plasma in Covid-19 severe pneumonia. N Engl J Med 2021;384:619-29. . doi: 10.1056/NEJMoa2031304 pmid: 33232588

84 Tabarsi P, Barati S, Jamaati H, etal. Evaluating the effects of intravenous immunoglobulin (IVIg) on the management of severe COVID-19 cases: A randomized controlled trial. Int Immunopharmacol 2021;90:107205. doi: 10.1016/j.intimp.2020.107205. pmid: 33214093

85 Torres Zambrano GM, Rivero RA, Villegas Valverde CA, etal. Features and outcomes of secondary sepsis and urinary tract infections in COVID-19 patients treated with stem cell nebulization.medRXiv 2020:2020.12.05.20244483. doi: 10.1101/2020.12.05.20244483
86 Weinreich DM, Sivapalasingam S, Norton T, etal. REGEN-COV antibody cocktail in outpatients with Covid-19.medRxiv 2021:2021.06.09.21257915. doi: 10.1101/2021.06.09.21257915

87 Weinreich DM, Sivapalasingam S, Norton T, etal. REGEN-COV antibody cocktail clinical outcomes study in Covid-19 outpatients.medRxiv 2021:2021.05.19.21257469. doi: 10.1101/2021.05.19.21257469

88 Yendry Ventura C, Fatima Mohammed A, Yandy Marx Castillo A, etal. Safety and efficacy of autologous non- hematopoietic enriched stem cell nebulization in Covid-19 patients. a randomized clinical trial, Abu Dhabi 2020. Research Square 2021; doi: 10.21203/rs.3.rs-558653/v1

89 Simonovich VA, Burgos Pratx LD, Scibona P, etalPlasmAr Study Group. A randomized trial of convalescent plasma in Covid-19 severe pneumonia. N Engl J Med 2021;384:619-29. doi: 10.1056/NEJMoa2031304. pmid: 33232588

90 Planas D, Veyer D, Baidaliuk A, etal. Reduced sensitivity of SARS-CoV-2 variant Delta to antibody neutralization. Nature 2021;596:276-80. . doi: 10.1038/s41586-021-03777-9 pmid: 34237773

91 Hoffmann M, Hofmann-Winkler H, Krüger N, etal. SARS-CoV-2 variant B.1.617 is resistant to bamlanivimab and evades antibodies induced by infection and vaccination. Cell Rep 2021;36:109415. . doi: 10.1016/j.celrep.2021.109415 pmid: 34270919

92 Chai KL, Valk SJ, Piechotta V, etal. Convalescent plasma or hyperimmune immunoglobulin for people with COVID-19: a living systematic review. Cochrane Database Syst Rev 2020;10:CD013600. doi: 10.1002/14651858.CD013600.pub3. pmid: 33044747

93 O Murchu E, Spillane S, Byrne P, O’Neill M, Harrington P, Ryan M. Interventions in an ambulatory setting to prevent progression to severe disease in patients with COVID-19: a systematic review. Ann Pharmacother 2021;10600280211028242. doi: 10.1177/10600280211028242. pmid: 34157890

94 Guyatt GH, Oxman AD, Vist G, etal. GRADE guidelines: 4. Rating the quality of evidence--study limitations (risk of bias). J Clin Epidemiol 2011;64:407-15.

doi: 10.1016/j.jclinepi.2010.07.017 pmid: 21247734

Supplementary material: Details of search strategies, excluded studies, study charcteristics, risk of bias assessments, network plots, complete network meta-analysis results and protocol

This is an Open Access article distributed in accordance with the Creative Commons Attribution Non Commercial (CC BY-NC 4.0) license, which permits others to distribute, remix, adapt, build upon this work non-commercially, and license their derivative works on different terms, provided the original work is properly cited and the use is non-commercial. See: http://creativecommons.org/licenses/bync/4.0/. 


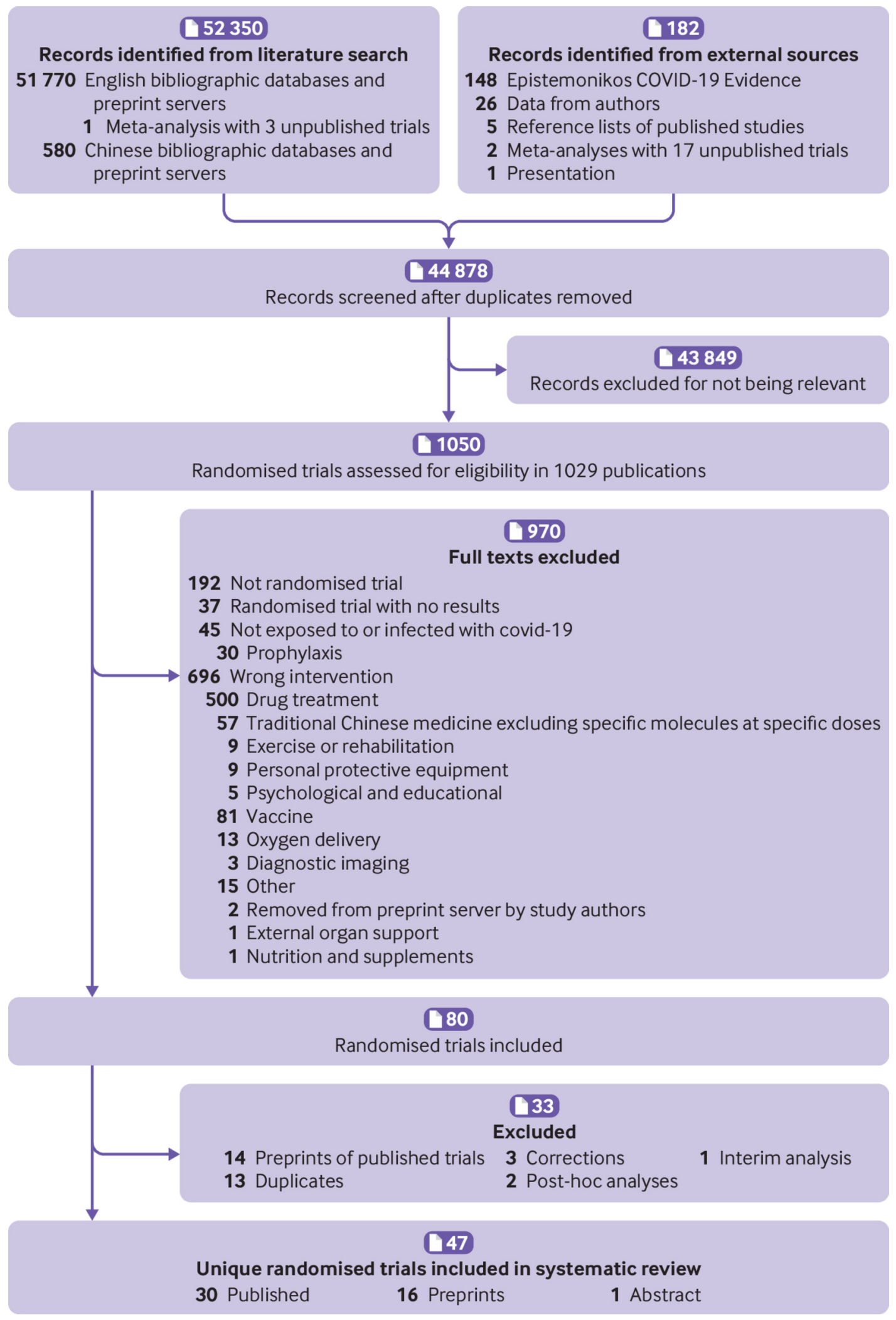

Fig 1 | Study selection for inclusion in review of antibody and cellular therapies for treatment of covid-19 


\begin{tabular}{|c|c|c|c|c|c|c|c|c|c|c|c|c|c|}
\hline & Mortality & $\begin{array}{l}\text { Mechanical } \\
\text { ventilation }\end{array}$ & $\begin{array}{l}\text { Admission } \\
\text { to hospital }\end{array}$ & $\begin{array}{l}\text { Viral } \\
\text { clearance } \\
\text { at } 7 \text { days }\end{array}$ & $\begin{array}{l}\text { Adverse } \\
\text { events* }\end{array}$ & $\begin{array}{c}\text { Infusion } \\
\text { reactions* }\end{array}$ & TRALI* & TACO* & $\begin{array}{c}\text { Duration } \\
\text { of hospital- } \\
\text { isation }\end{array}$ & $\begin{array}{l}\text { Time to } \\
\text { symptom } \\
\text { resolution }\end{array}$ & $\begin{array}{c}\text { Time } \\
\text { to viral } \\
\text { clearance }\end{array}$ & $\begin{array}{l}\text { Ventilator } \\
\text { free days }\end{array}$ & $\begin{array}{l}\text { ICU } \\
\text { length } \\
\text { of stay }\end{array}$ \\
\hline \multicolumn{14}{|c|}{ Non severe disease } \\
\hline Standard care $\dagger$ & 3 per 1000 & 6 per 1000 & 60 per 1000 & 160 per 1000 & & & & & 14 days & 9 days & 24 days & & \\
\hline Bamlanivimab & $\begin{array}{c}-2(-3 \\
\text { to } 82) \neq\end{array}$ & & $\begin{array}{c}-41(-57 \\
\text { to }-6)\end{array}$ & \begin{tabular}{|c|}
$2(-113$ \\
to 216$)$
\end{tabular} & & & & & & $\begin{array}{l}-1(-3 \\
\text { to } 3)\end{array}$ & $\begin{array}{l}4(-15 \\
\text { to } 43)\end{array}$ & & \\
\hline $\begin{array}{l}\text { Bamlanivimab, } \\
\text { etesevimab }\end{array}$ & $\begin{array}{l}-3(-3 \\
\text { to } 0) \neq\end{array}$ & & $\begin{array}{c}-38(-54 \\
\text { to }-9)\end{array}$ & $\begin{array}{l}57(-100 \\
\text { to } 319)\end{array}$ & & & & & & $\begin{array}{l}-1(-3 \\
\text { to } 1)\end{array}$ & $\begin{array}{l}1(-16 \\
\text { to } 35)\end{array}$ & & \\
\hline $\begin{array}{l}\text { Casirivimab, } \\
\text { imdevimab }\end{array}$ & $\begin{array}{l}-1(-3 \\
\text { to } 1) \neq\end{array}$ & $\begin{array}{l}-4(-6 \\
\text { to } 2)\end{array}$ & $\begin{array}{l}-42(-50 \\
\text { to }-30)\end{array}$ & & & & & & & $\begin{array}{l}-2(-4 \\
\text { to }-1)\end{array}$ & & & \\
\hline $\begin{array}{l}\text { Convalescent } \\
\text { plasma }\end{array}$ & $\begin{array}{l}-1(-2 \\
\text { to } 2) \neq\end{array}$ & $\begin{array}{l}-1(-5 \\
\text { to } 4)\end{array}$ & & $\begin{array}{l}132(-15 \\
\text { to } 348)\end{array}$ & & & & & $\begin{array}{l}-4(-10 \\
\text { to } 1)\end{array}$ & & & & \\
\hline $\begin{array}{l}\text { CT-P59 } \\
\text { monoclonal } \\
\text { antibody }\end{array}$ & to 90$) \neq$ & \begin{tabular}{|c|}
$4(-7$ \\
to 231$) \neq$
\end{tabular} & $\begin{array}{c}-24(-52 \\
\text { to } 37)\end{array}$ & $\begin{array}{l}94(-72 \\
\text { to } 352)\end{array}$ & & & & & & $\begin{array}{l}-3(-5 \\
\text { to } 0)\end{array}$ & $\begin{array}{l}3(-16 \\
\text { to } 40)\end{array}$ & & \\
\hline Sotrovimab & $\begin{array}{c}-2(-3 \\
\text { to } 29) \neq \\
\end{array}$ & $\begin{array}{l}-6(-6 \\
\text { to }-4) \neq\end{array}$ & $\begin{array}{l}-48(-58 \\
\text { to }-25)\end{array}$ & & & & & & & & & & \\
\hline \multicolumn{14}{|c|}{ Severe or critical disease } \\
\hline Standard care $\dagger$ & 220 per 1000 & 300 per 1000 & & & & & & & 12 days & & & 14 days & 4 days \\
\hline $\begin{array}{l}\text { Casirivimab, } \\
\text { imdevimab }\end{array}$ & \begin{tabular}{|c|}
$-7(-79$ \\
to 82$)$
\end{tabular} & & & & & & & & & & & & \\
\hline Control plasma & $\begin{array}{l}118(-41 \\
\text { to } 307)\end{array}$ & & & & & & & & & & & & \\
\hline $\begin{array}{l}\text { Convalescent } \\
\text { plasma }\end{array}$ & $\begin{array}{c}-14(-56 \\
\text { to } 20)\end{array}$ & $\begin{array}{c}-14(-135 \\
\text { to } 115)\end{array}$ & & & & & & & $\begin{array}{l}-1(-2 \\
\text { to } 1)\end{array}$ & & & $\begin{array}{r}-1(-2 \\
\text { to } 0)\end{array}$ & $\begin{array}{c}1(-2 \\
\text { to } 0) \neq\end{array}$ \\
\hline $\begin{array}{l}\text { Intravenous } \\
\text { immunoglobulin }\end{array}$ & \begin{tabular}{|c|}
$-53(-119$ \\
to 29)
\end{tabular} & \begin{tabular}{|c|}
$-70(-190$ \\
to 80$)$
\end{tabular} & & & & & & & $\begin{array}{l}-2(-6 \\
\text { to } 2)\end{array}$ & & & & \\
\hline \multicolumn{14}{|c|}{ All severities } \\
\hline Standard care $\dagger$ & & & & & 0 per 1000 & 3 per 1000 & 0 per 1000 & 0 per 1000 & & & & & \\
\hline Bamlanivimab & & & & & $\begin{array}{c}-2(-12 \\
\text { to } 9)\end{array}$ & \begin{tabular}{|c|}
$3(-1$ \\
to 10$)$
\end{tabular} & & & & & & & \\
\hline $\begin{array}{l}\text { Bamlanivimab, } \\
\text { etesevimab }\end{array}$ & & & & & & $\begin{array}{l}5(-2 \\
\text { to } 27) \\
\end{array}$ & & & & & & & \\
\hline $\begin{array}{l}\text { Casirivimab, } \\
\text { imdevimab }\end{array}$ & & & & & $\begin{array}{r}-2(-4 \\
\text { to } 0)\end{array}$ & $\begin{array}{l}6(-1 \\
\text { to } 29)\end{array}$ & & & & & & & \\
\hline Control plasma & & & & & & $\begin{array}{c}8(-2 \\
\text { to } 45)\end{array}$ & & & & & & & \\
\hline $\begin{array}{l}\text { Convalescent } \\
\text { plasma }\end{array}$ & & & & & $\begin{array}{l}2(-31 \\
\text { to } 34)\end{array}$ & $\begin{array}{l}6(1 \\
\text { to } 18) \\
\end{array}$ & $\begin{array}{l}0(-5 \\
\text { to } 6)\end{array}$ & $\begin{array}{l}5(-1 \\
\text { to } 12) \\
\end{array}$ & & & & & \\
\hline $\begin{array}{l}\text { CT-P59 } \\
\text { monoclonal } \\
\text { antibody }\end{array}$ & & & & & & $\begin{array}{l}-1(-2 \\
\text { to } 7)\end{array}$ & & & & & & & \\
\hline \begin{tabular}{l|} 
Intravenous \\
immunoglobulin
\end{tabular} & & & & & $\begin{array}{l}25(-14 \\
\text { to } 64)\end{array}$ & & & & & & & & \\
\hline $\begin{array}{l}\text { Puried equine } \\
\text { anti-RBD }\end{array}$ & & & & & $\begin{array}{l}0(-16 \\
\text { to } 16)\end{array}$ & & & & & & & & \\
\hline Sotrovimab & & & & & & $\begin{array}{c}0(-2 \\
\text { to } 14)\end{array}$ & & & & & & & \\
\hline \multicolumn{14}{|c|}{ than standard care } \\
\hline \multicolumn{14}{|c|}{ High/moderate certainty } \\
\hline \multicolumn{14}{|c|}{ Low certainty } \\
\hline \multicolumn{4}{|c|}{ Very low certainty } & & & & & & & & & & \\
\hline
\end{tabular}

* Based on directm (pairwise) estimate of effect rather than network estimate

$\dagger$ Expected risk of each outcome with standard care is reported in grey row. Numbers incoloured cells areestimated risk differences $(95 \% \mathrm{Cl})$ per 1000 patients or mean difference $(95 \% \mathrm{Cl})$ in days when compared to standard care

‡ Because we expected that there would be no effect modification, this outcome was not analyzed according to disease severity

Fig 2 | Summary of effects compared with standard care of antibody and cellular therapies for treatment of covid-19 